\title{
Communicating with Muslim parents: "the four principles" are not as culturally neutral as suggested
}

\author{
Anna E. Westra • Dick L. Willems • Bert J. Smit
}

Received: 13 November 2008 / Accepted: 3 March 2009/Published online: 21 March 2009

(C) The Author(s) 2009. This article is published with open access at Springerlink.com

\begin{abstract}
The "four principles approach" has been popularly accepted as a set of universal guidelines for biomedical ethics. Based on four allegedly trans-cultural principles (respect for autonomy, nonmaleficence, beneficence and justice), it is supposed to fulfil the need of a 'culturally neutral approach to thinking about ethical issues in health care'. On the basis of a case-history, this paper challenges the appropriateness of communicating in terms of these four principles with patients with a different background. The case describes the situation in which Muslim parents bring forward that their religion keeps them from consenting to end-of-life decisions by non-religious paediatricians. In a literature analysis, the different meanings and roles of the relevant principles in non-religious and Islamic ethics are compared. In non-religious ethics, the principle of nonmaleficence may be used to justify withholding or withdrawing futile or damaging treatments, whereas Islamic
\end{abstract}

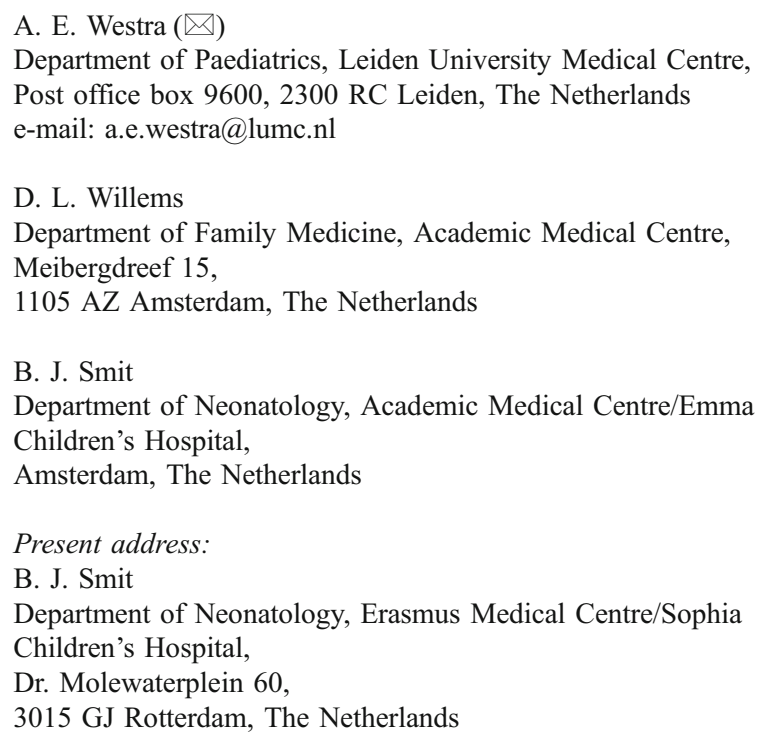

ethics applies this principle to forbid all actions that may harm life. And while the non-religious version of the principle of respect for autonomy emphasises the need for informed consent, the Islamic version focuses on "respect for the patient". We conclude that the parties involved in the described disagreement may feel committed to seemingly similar, but actually quite different principles. In such cases, communication in terms of these principles may create a conflict within an apparently common conceptual framework. The four principles approach may be very helpful in analysing ethical dilemmas, but when communicating with patients with different backgrounds, an alternative approach is needed that pays genuine attention to the different backgrounds.

Keywords Ethics · Communication · Islam · Intensive care unit, neonatal Principle-based ethics

\section{Introduction}

Most decisions to withhold or withdraw life-sustaining treatment from (newborn) infants are made with mutual consent of both physicians and parents [10, 15]. In the context of the multiculturalism of most Western European countries it is unlikely, however, that physicians and parents will always hold the same values. They may have conflicting perceptions about which course of action is in the best interest of the critically and incurably ill child.

The discussion and solution of these and similar disagreements call for a bioethical approach that helps identifying and evaluating the different arguments concerned. The four principles approach, introduced by T.L. Beauchamp and J.F. Childress in 1979 and promoted in Europe by R. Gillon, seems the most promising candidate $[2,13]$. It claims that 
'whatever our personal philosophy, politics, religion, moral theory, or life stance, we will find no difficulty in committing ourselves to four prima facie moral principles' [13]. These four allegedly trans-cultural principles (respect for autonomy, nonmaleficence, beneficence and justice) would offer a common set of moral commitments, a common moral language and a common set of moral issues. This then would fulfil the need of a 'culturally neutral approach to thinking about ethical issues in health care' [13]. The four principles approach has often been criticised, e.g. because conflicts between the four principles seem unsolvable, since there is no unified moral theory from which they are all derived [9]. Nevertheless, the approach has been popularly accepted as a set of universal guidelines for bioethics, especially in medical circles.

On the basis of a case-history (described in the case report), this paper challenges the appropriateness of communicating in terms of these four principles with parents with a different background. The case describes the situation when Muslim parents bring forward that their religion keeps them from consenting to end-of-life decisions of non-religious paediatricians. In Western Europe, Muslims form a large religious minority. The term "non-religious ethics" is used to indicate forms of ethics not explicitly based on religious texts or beliefs.

First we shall give a brief outline of the four principles approach, often referred to as "principlism". This same paragraph will mirror the non-religious meanings and roles of the principles. Subsequently, we will describe the different meanings and roles of the principles in Islamic ethics. This will reveal that the parties involved in the described disagreement may feel committed to seemingly similar, but actually quite different principles.

\section{The four principles approach to biomedical ethics}

The four principles approach is steeped in common morality. This is, as Beauchamp and Childress put it, the unphilosophical common sense and tradition shared generally by the members of a society. The common morality comprises all and only those norms that all morally serious persons accept as authoritative. By contrast, morality in the community-specific sense includes the moral norms that spring from particular cultural, religious, and institutional sources [3]. Beauchamp and Childress accept the fact that morality in the community-specific sense reflects significant cultural differences, but also believe that a set of four general principles, shared by everyone regardless of their background, could form the basis of a culturally neutral approach to bioethical issues [3].

One of these principles, justice, has little relevance for the disagreement we focus on in this paper and we shall therefore refrain from discussing it. Beauchamp and Childress describe the three other principles as follows [4-6].

Throughout the history of health care, the professional's obligations and virtues have been interpreted as commitments of beneficence. This principle refers to actions performed that contribute to the welfare of others. Traditionally physicians were just "doing good". It has become understood, however, that acts of beneficence can conflict with the requirement to respect a patient's autonomy. This principle refers to the individual's self-determination, free from control and influence by others. In the patient-physician relationship, the patient's autonomy is firstly based on informed consent and refusal. If minors are involved, the child's autonomy and accessory rights are assigned to the parents. Some principlists regard the principle of respect for autonomy as "first among equals" [14].

The principle of nonmaleficence is closely related to beneficence; it asserts an obligation not to inflict harm intentionally. Beauchamp and Childress emphasise that when medical treatment is futile or when its burdens outweigh the benefits, the principle of nonmaleficence might justify or sometimes even require withholding or withdrawing lifesustaining procedures. Arguing that treatment occasionally violates a patient's interests, the principlists give considerable weight to quality-of-life judgements.

Beauchamp and Childress consider the four principles as "prima facie" rules, which means that they are nonabsolute: each of them is binding unless it conflicts with another [3]. Conflicting principles call for careful "balancing and overriding": the balancing of the respective weights of the competing principles to determine one's actual obligations. "Specification" must be used to reduce the abstractness of the principles; to provide them with actionguiding content [3]. This process of specification is contextrelated and may also be influenced by one's particular cultural or religious background, i.e. by one's morality in the community-specific sense. This means that the same principle can be translated into various forms of actual guidance. Moral justification proceeds from a "coherence model" that provides principles for specific cases and illuminates case analysis from general principles [7].

\section{The four principles rooted in Islamic ethics}

The Islamic tradition (The Qur'an, the sayings of prophet Muhammed and the interpretative literature derived from them) offers Muslims a guide for all aspects of life. The main Islamic guiding principles are respect for human dignity and the maintenance and protection of life, property and honour. Several authors claim that the roots of the four principles of Beauchamp and Childress are clearly 
identifiable in Islamic tradition as well [1, 17]. Van Bommel suggests that these four principles even summarise the Islamic norms of care and concern in medicine [8].

The way Beauchamp and Childress present the four principles (as summarised above) mirrors certain aspects of their own morality. Having a similar background as the principlists, many non-religious Western European paediatricians will attach the same meaning to these principles. Some of these principles nevertheless appear to have essentially different meanings in Islamic ethics.

Aksoy and Elmai, for example, demonstrate that Islamic tradition offers many statements relating to the principle of nonmaleficence, in the sense of refraining from doing harm to others [1]. Refraining from treatment that might cause or prolong harm, however, is generally not a topic in Islamic medical ethics. Because of the unconditional valuation of human life, every additional day lived is of value; a treatment that prolongs life therefore cannot be harmful. The trust in an omnipotent God is a second reason why decisions to forgo life-prolonging treatments cannot be justified. Van Bommel: 'Muslims feel very strong that it is Allah who does the actual healing, the doctor being only the agent for the will of Allah. This consciousness is based on the Qur'anic verse: "If Allah touch you with affliction, none can remove it but He." (6:17) [8]. Only incidentally a Muslim scholar or a group of paediatricians will assert that this does not necessarily rule out the possibility to refrain from treatment $[11,16]$.

Aksoy and Elmai also give many instances in which Islamic tradition shows respect for a patient's autonomy [1]. Likewise, many Muslims defend the point of view that a religious morality is not incompatible with human freedom and responsibility $[8,12,17]$. 'The Qu'ran puts its trust in the rational power of human beings to distinguish between truth and falsehood', says Van Bommel [8]. Ebrahim explains: 'Reason was given to man so that he may be in a position to freely accept the Law and obey Allah, or not to do so at all.'; and 'If he would not be free, the burden of responsibility and morality would not have been placed upon him [12].'

But does this Islamic autonomy authorise Muslims to make their own decisions about life and death? Aksoy and Elmai acknowledge that 'absolute knowledge is predominant over individual autonomy [1].' This view is endorsed by Van Bommel: 'For a Muslim patient, absolute autonomy is very rare, there will be a feeling of responsibility towards God, and he or she lives in a social coherence, in which influences of the imam and relatives play their roles [8].' Consequently, personal choices are only accepted if they are the "right" ones. Questionable decisions that would be acceptable according to the non-religious variant of respect for autonomy, cannot be permitted according to the Islamic variant. In such cases the Islamic notion of respect for the patient requires to oppose the patient's self-determination. The emphasis is on beneficence over autonomy [1]. For in protecting patients from making questionable choices, the doctor shows respect for the patient as a person. Many nonreligious doctors would call this paternalism.

One could say that non-religious ethics applies the principle of nonmaleficence to justify withholding or withdrawing futile or damaging medical treatment, whereas in Islamic ethics it is used to forbid all kind of actions or omissions that may harm life. And while the non-religious version of the principle of respect for autonomy emphasises the need for informed consent, the Islamic version focuses on the first part of the principle: respect.

\section{Discussion}

Clearly, the Muslim parents and non-religious paediatricians who disagree on which course of action would be in the best interest of their critically and incurably ill child may feel committed to seemingly similar, but actually quite different principles. The paediatricians may apply the principle of nonmaleficence to justify withdrawing lifesustaining treatment and may be convinced they need an explicit consent for this from the parents in order to respect their autonomy. The parents, however, do not consider the extra days harm and trust their omnipotent God, which keeps them from making decisions about life and death. In such situations, communication in terms of these principles may create a conflict (as described in the case-history) within an apparently common conceptual framework. This is not the legitimate agreement one might be looking for.

When paediatricians do not hold the same values as (the parents of) their patients, an approach based on a search for shared beliefs is in itself not impossible, as certain beliefs can be justified from different outlooks on life. However, when the difference in background between physicians and patients is substantial, an alternative approach may be needed that pays genuine attention to the different backgrounds instead of putting them between brackets.

First of all, a more sophisticated terminology is required. The non-religious paediatricians could for instance emphasise the "natural" character of the suggested path, rather than explaining that they would like to "give the child the chance to die". This would leave some room for hope, within the limits of what we as physicians can humanly do for the child. In addition, it may often be necessary to clarify expressions used, for some meanings, such as those of "unnecessary suffering" and "quality of life", are far from universal. Sometimes it may be enough to realise that differences do exist; being aware that some terms may be interpreted differently is an important step in achieving effective terminology when addressing parents. 
Secondly, caution is required regarding the explicitness and time process of the desired consent. Many Western physicians tend to involve patients and their families as much as possible in the decision process, while Muslim parents believe that life and death are decided by Allah only. Without challenging the decision, Muslim parents sometimes declare that for religious reasons explicit consent is not possible. It must be clear what the options are in such situations. Regarding the time process, it may be helpful to slow down the pace: if it seems difficult to come to a consensus on a certain day, it may be possible after one or two more days of reflection.

In our experience, the approach we put forward can even result in consent to the proposed end-of-life decision. It demands from paediatricians a sincere interest in the differences between normative standpoints related to cultural or religious beliefs and dedicated efforts to grasp these. Undoubtedly this will not always lead to unanimity, but a transparent disagreement would seem preferable to a conflict situation.

\section{Case report}

A Turkish woman, mother of three healthy children, gave birth to twins at 29 weeks' gestational age. The secondborn twin was a girl with birth weight $945 \mathrm{~g}$. Apgar scores were 8 and 9 after 1 and 5 min, respectively. No abnormalities were found at physical examination. The girl was admitted on a level III neonatal intensive care unit.

After a mild respiratory distress syndrome (RDS), for which treatment with continuous positive airway pressure was initiated, she developed necrotising enterocolitis only 10 days after birth. She needed mechanical ventilation. Laparotomy was performed with major bowel resection and creation of a double-sided stoma.

Despite high caloric intake, partially parenterally, the girl hardly gained weight, possibly due to high stomal output. A small-intestine anastomosis was made, but shortly after, a relaparotomy was needed because of a severely painful bloated belly and abdominal wound leakage. The wound was sealed but burst open again. After a repetition of this event conservative treatment was given. The belly wound stayed open.

The girl's clinical condition deteriorated rapidly. Mechanical ventilation had been reinitiated because of an acute RDS and the high settings could not be decreased. Infections were difficult to treat and enteral feeding was no option anymore. At age 4 months the girl weighed $400 \mathrm{~g}$ more than at birth, but this gain was mainly the result of oedema.

Gradually, the medical team came to realise that further treatment offered no chance of survival: the open belly and other complications would not recover and would cause her death in the near future. The medical team felt that life- sustaining treatment should be withdrawn, because prolonging would harm the girl.

When the doctors discussed their opinion with the parents and asked for their explicit consent, the parents explained that because of their Islamic religious beliefs, they would not consent to this strategy. Explanation of the team's motives in terms of "nonmaleficence" and "respect for autonomy", two of the 'four principles of biomedical ethics', evoked resistance from the parents. The conversation resulted in a conflict, which could only be solved through the agency of an external paediatrician: the parents agreed to respect his second opinion and did not raise objections at the time this opinion turned out to be similar to the one made by their own medical team.

Acknowledgements We are grateful for the helpful comments on earlier drafts of this manuscript by Adem Kose, imam of the Academic Medical Centre Amsterdam and Nordin Dahhan, paediatrician Sint Lucas/Andreas Hospital Amsterdam.

\section{Conflicts of interest None.}

Open Access This article is distributed under the terms of the Creative Commons Attribution Noncommercial License which permits any noncommercial use, distribution, and reproduction in any medium, provided the original author(s) and source are credited.

\section{References}

1. Aksoy S, Elmai A (2002) The core concepts of the 'four principles' of bioethics as found in Islamic tradition. Med Law 21:211-224

2. Beauchamp TL, Childress JF (2006) Principles of biomedical ethics, 5th edn. Oxford University Press, New York

3. Beauchamp TL, Childress JF (2006) Moral norms. In: Beauchamp TL, Childress JF (eds) Principles of biomedical ethics, 5th edn. Oxford University Press, New York, pp 1-25

4. Beauchamp TL, Childress JF (2006) Beneficence. In: Beauchamp TL, Childress JF (eds) Principles of biomedical ethics, 5th edn. Oxford University Press, New York, pp 165-224

5. Beauchamp TL, Childress JF (2006) Respect for autonomy. In: Beauchamp TL, Childress JF (eds) Principles of biomedical ethics, 5th edn. Oxford University Press, New York, pp 57-112

6. Beauchamp TL, Childress JF (2006) Nonmaleficence. In: Beauchamp TL, Childress JF (eds) Principles of biomedical ethics, 5th edn. Oxford University Press, New York, pp 113-164

7. Beauchamp TL, Childress JF (2006) Method and moral justification. In: Beauchamp TL, Childress JF (eds) Principles of biomedical ethics, 5th edn. Oxford University Press, New York, pp 384-414

8. van Bommel A (1999) Medical ethics from the Muslim perspective. Acta Neurochir Suppl (Wien) 74:17-27

9. Clouser D, Bernard G (1990) A critique of principlism. J Med Philos 15:219-236

10. Cook LA, Watchko JF (1996) Decision making for the critically ill neonate near the end-of-life. J Perinatol 16:133-136

11. da Costa DE, Ghazal H, Al Khusaiby S (2002) Do Not Resuscitate orders and ethical decisions in a neonatal intensive care unit in a 
Muslim community. Arch Dis Child Fetal Neonatal Ed 86:F115F119. doi:10.1136/fn.86.2.F115

12. Ebrahim A (2003) Islamic ethics. In: Ebrahim A (ed) Biomedical ethics: Islamic perspective. Nordeen, Kuala Lumpur, pp 11-21

13. Gillon R (1994) Medical ethics: four principles plus attention to scope. BMJ 309:184-188

14. Gillon R (2003) Ethics needs principles - four can encompass the rest-and respect for autonomy should be "first among equals". J Med Ethics 29:307-312. doi:10.1136/jme.29.5.307
15. van der Heide A, van der Maas PJ, van der Wal G, Kollée LA, de Leeuw R, Holl RA (1998) The role of parents in end-of-life decisions in neonatology: physicians' views and practices. Pediatrics 101:413-418. doi:10.1542/peds.101.3.413

16. Rahman F (2006) Health and medicine in the Islamic tradition: change and identity. Crossroad, New York

17. Serour GI (1994)) Islam and the four principles. In: Gillon R (ed) Principles of healthcare ethics. Wiley, Chichester, pp 75-91. doi:10.1007/s00431-009-0971-7 